\title{
Business Modelling as a Way Forward for Strategic Management Processes - A Case Study of SME's
}

\author{
Anders Bille Jensen \\ University of Southern Denmark, Department of Marketing \& Management, \\ Sdr. Stationsvej 28, 4200 Slagelse, Denmark \\ E-mail:abj@sdu.dk
}

Received 9 March 2016; Accepted 10 March 2016; Publication 25 April 2016

\begin{abstract}
This comparative case study contributes to understanding the process of business modelling in small and medium sized companies. The study analyses and discusses how three companies applied a general business model framework for explicating and modelling their businesses. The study is based on data collected during a "live" business modelling process in existing firms. This addresses a general and combined gap in the literature on application of artefacts in business modelling, on insights in strategy processes, and on the role of actors. It is argued that business models may be linked to three distinctively different roles in strategizing; 1) for development, 2) for innovative or 3) for alignment purposes. These different roles have implications for the relation to the logic of the business model as well as the process. From a practical perspective a bold proposition could be that continuous and agile modelling within a scalable business model conceptualization can enable consolidation and accumulation of learning which can lead to stronger strategic leadership than traditional and formal processes. Such modelling processes may suit particularly well as a way forward for small and medium sized companies.
\end{abstract}

Keywords: Business model, management, strategic management, strategizing, organization, decision making, organizational learning.

Journal of Multi Business Model Innovation and Technology, Vol. 4, 1-34.

doi: 10.13052/jmbmit2245-456X.411

(c) 2016 River Publishers. All rights reserved. 


\section{Introduction: The Business Model Approach in Strategic Management Processes}

The article pursues the proposition that business model concepts and in particular the process of "modelling" plays an important role for the strategic management of small and medium sized companies. This case study investigates the strategy process and strategizing activities in smaller organizations which face the challenge of building sustainable strategy practices. More specifically this becomes relevant when the strategy work extends beyond the individual manager by the involvement of the management team, the employees, the board and other primary stakeholders. Strategy is here understood as activities which are carried out with the intention to improve a situation for the benefit of the company and its stakeholders. Strategies are therefore based on more or less known and explicit causalities between activity and expected results. Due to their futuristic orientation and the (dynamic) uncertainties related to contexts and causality, strategies have a theoretical, hypothetical element $[1,2]$.

The current language of strategy is complex. Basic textbooks easily exceed 500 pages of models and tools [3-5]. It has become a challenge and discipline of an expert to pick and apply the appropriate ones. The involvement of other stakeholders such as financiers, employees, customers and possible partners adds to the complexity due to varieties or lack of training in strategy. In all situations remain the challenge to develop a common language and process for a specific organization. Occasionally, consultants are hired to "run" the strategy process but such approaches have been criticized for being costly and difficult to anchor in the organization. Another aspect is that many strategy tools reflect the practices of larger, hierarchical organizations which may not be well suited for increasingly dynamic environments [6,7]. Additionally, such strategy tools may not be particularly relevant for smaller companies which may have a smaller and less stable business and dependence on a narrow range of customers, people, a limited technology base, and few relational resources. Smaller organizations do often not have the resources or competencies for developing their management processes, and the strategizing process becomes very dependent on the manager or another key person. Often, strategy becomes very operationally oriented, and doesn't explore or exploit the full range of options. Many companies fail to develop a "strategic language" resulting in either too simplistic (e.g. pure financial) views, or very text rich documents without a coherent framework - or simply, take an emergent approach to strategizing in which a myriad of operational and tactical initiatives are taken at 
the cost of building a stronger strategic position. The growth of organizations, however, requires a shared and to some extent stable view of realities (a shared, or "collective mind") and options in order to establish and reach its goals through coordinated and coherent efforts. Consequently, managers face a complex challenge involving plan, ploy, patterns, positions and perspectives [8] mixed with everyday tasks.

The interest for business models has been growing in the last two decades. This has led to many discussions on what business models are [9-11] and what their roles are $[12,13]$ and the value of them $[14,15]$. Consequently, business models can be seen as a core unit of analysis [16] extending beyond the firm boundaries [17]. Business models can be a mean for commercializing new technologies $[18,19]$. Business models can also be seen as a construct between strategy and implementation [9]. Business models can therefore be subject for innovation themselves, or a template for implementing initiatives [20]. They can be used to depict current realities ("as is") or used to decide on a preferred future ("to be") [21, 22], i.e. as role exemplars [9]. Business models (real) can then be seen as a representation of strategic decisions which have been implemented through tactical choices in processes and resources [23], which may even create self-supporting "virtuous circles" [24]. Business models can also have a narrative role [25], serving as boundary objects [13] and as conventions [26] in which stakeholders become motivated to participate in the joint realization of a venture. The business model concept is therefore a highly elastic concept.

For the purpose of this paper we apply an understanding of business models as the core logic of value creation, value delivery and value capture of a focal firm in its stakeholder network. This understanding is in line with the recurring elements of what constitute a business model [10, 11, 26, 27] and situates the business model as the central unit of the strategizing efforts of the company.

The strategic nature of business models has been emphasized theoretically but the actual role of business models in managerial processes and languages of the firm has been relatively un-examined. The same lack of understanding of internal processes and the role of actors apply to the strategy field in general [28-31]. One reason for this may be the difficulty in accessing internal and ongoing strategy processes in established firms. Further, processes are difficult to research as they relate to multiple levels of analysis, are contextual, involve non-linear connections to outcomes and issues of time and temporality [32]. It is therefore not surprising that for established businesses most research is viewing one or more cases through an ex post lens often 
with a dominant representational view on business models. It is, however, increasingly being acknowledged that there are significant differences between business model innovation (in the meaning of creating new business models), and the development of existing business models [33, 34]. Studying the process of explicating the business model may provide insights on several interesting questions, such as, but not limited to: How are strategy options created? How are they related to the business modeling? What is the balance between the traditional process (modeling) and content (the model) question? How do actors perceive and work with a business model tool? Are there any barriers in the modeling process? What tasks or roles does the business model perform in the strategizing efforts?

This paper address the general question of how management can explicate their business models and improve their strategy processes, and more specifically the research question as to "if - and - to which extent - can the business model concept facilitate the strategic development in small and medium sized companies".

This case research is based on three companies and offers an "inside view" of the impact of explicitly applying the business model approach in a real life setting. The point of view is pragmatic, emphasizing practitioners' efforts of solving managerial challenges in their businesses. The aim is to monitor the process and more generally explain the developments through theoretical reflection and potential generalizations extending beyond the selected cases.

\subsection{Business Models - Articulation and Application}

As Chesbrough [12] noted: "Every company has a business model, whether they articulate it or not". Since business models are complex constructs they can be articulated in different ways depending on purpose. One popular approach is the business model canvas developed by Osterwalder and colleagues $[21,27]$. The business model canvas builds on a systematic review, resulting in 9 components of a business model, which are often graphically depicted in the business model canvas.

The business model canvas offers a framework which allows first step of implementation of a strategy discipline which may appear extensive and complex. First, it is a general framework making it applicable in many settings. It applies a terminology based on prior literature and theories which makes it easy to access. A related advantage is the "scalability" of the framework; it can be applied in various depths, ranging from the intuitive level to being supported by in-depth analysis of its components and their relations. 
In this process other established strategy tools may be included. The learning barriers of getting started are therefore considered low and the framework is a stable platform for possible expansion and elaboration. Further, the framework can be applied independently of time perspective, i.e. both for assessing the past, the current and the future (e.g. follow up on the "to be" business model). The business model canvas has proved to be quite popular. For above reasons, the framework has been applied in this project as a basic, underlying concept to explicate business models.

Osterwalder mentions the need for further empirical research for the canvas in his original Ph.D. thesis [21]. This call was repeated again in $2013^{1}$ with the opening of a Ph.D. position in his company. This paper, however, is not aimed at "testing" the canvas. Instead the canvas is applied to initiate a process in the companies, with the canvas at the center of the discussions and modeling process, including the purpose of mediating access to the hidden, unelaborated aspects of their business models. A specific, conceptualized model, as the canvas will influence the process and this will naturally be discussed. More broadly, the paper addresses a call for research on the application of artefacts in business modeling [35].

Next, the choice of methodology will be presented. Then follow the case presentations, the comparative case analysis and theoretical discussion. A synthesis is provided in order to understand the possible roles of business models in the strategizing efforts. Limitations and concluding remarks close the paper.

\section{Methodology}

\subsection{Research Design}

The research design can be characterized as an experiment of explicating business models of specific companies in their own conditions and contexts of development. The underlying pragmatic approach reflects the practice and realities of in situ "live" business modeling processes. Abduction, i.e. iterative cycles of combining theory and empirical evidence to build knowledge, was done during the process, both at case level and across-cases. Multiple (3) cases and a "replication logic" enriches the understanding in broadness and depth, reduces the likelihood for creation of association by chance and supports

\footnotetext{
${ }^{1}$ http://businessmodelalchemist.com/blog/2013/01/wanted-business-model-researcher-join -our-team.html
} 
emergent patterns by comparisons [36-38] of the cases and their contexts. Diversity in findings is rated equally important as consolidation due to the explorative and experimental nature of the project.

The recruitment of the case companies are based on; a) relevance to the topic of smaller companies in which there is no organizational unit dedicated to strategy formulation; b) the intrinsic motivation of one or more key actors in the companies to improve their strategy process; c) the possibility of getting access to data which are normally difficult to access from the outside of an organization. The companies are different in terms of products and markets, they are all well established, in a healthy financial situation, and they share the challenge of simultaneous balancing existing business models with new initiatives and limited resources. The cases are anonymous due to the sensitive nature of the topics. The companies are the cases, and the primary units of analysis are the business model and the processes of modeling it, and the study is therefore a multiple case study with embedded units of analysis [38]. The three cases are presented in the next section.

Research process: The initial step was to establish the current business model of the case companies by application of the business model canvas. From then on the overall research method was to follow the process and outcomes, including contextual and other changes to capture rival explanations of the changes. Soft interventions were done to facilitate the process. This was mainly through the introduction of the canvas, discussing options for applications, assist in trouble shooting, and exchanges of experience during the process but without determining the actual outcome of the process in the companies. This intervention must be characterized as soft, compared to more direct intervention of action research. The applied soft principle leaves no doubt as to who is researcher and who is "being researched" [39].

Data collection: The overall approach can be summarized as participative observation using the canvas model as previously described. Data was collected via documentary techniques, verbal communication and observational techniques which in combination provides a holistic picture and the possibility of validation; the more signs of change pointing in one direction the more valid the finding. This approach allows access to what Argyris and Schon refers to as "espoused theories" and "theories in use", respectively [40]. In line with the "strategy-as-a-practice" literature this approach emphasizes both macro and micro levels of data [30]. 
Data analysis and presentation: In the abductive approach data analysis takes place on an ongoing basis and theoretical frames and findings are increasingly crystalized through iterations between the empirical and the theoretical domains [41-43] building cohesiveness and parsimoniousness and reducing complexity and (unnecessary/redundant) data [41]. The first round of analysis typically generates insights close to the empirical domain, meaning that the terms, logics and structures are close to - and identifiable - by the participants. The following analysis typically aims at identifying higher order patterns $[43,44]$. The emphasis of the presentation in this paper is on the general findings, rather than the individual cases. The main findings will be structured according to key themes, integrating findings with theoretical discussions. For demonstration purposes examples are taken from the single cases, thereby drawing on the value of the "intrinsic case" $[38,45]$ of going in more detail of a specific case.

The companies have had the possibility to comment on data records and the final interpretation, resulting in quality improvements by complementing and correcting of data details, as well as deepening the analysis on selected points. The final interpretation and presentation remains the sole responsibility of the researcher.

This process is summarized in the conceptual map in Figure 1.

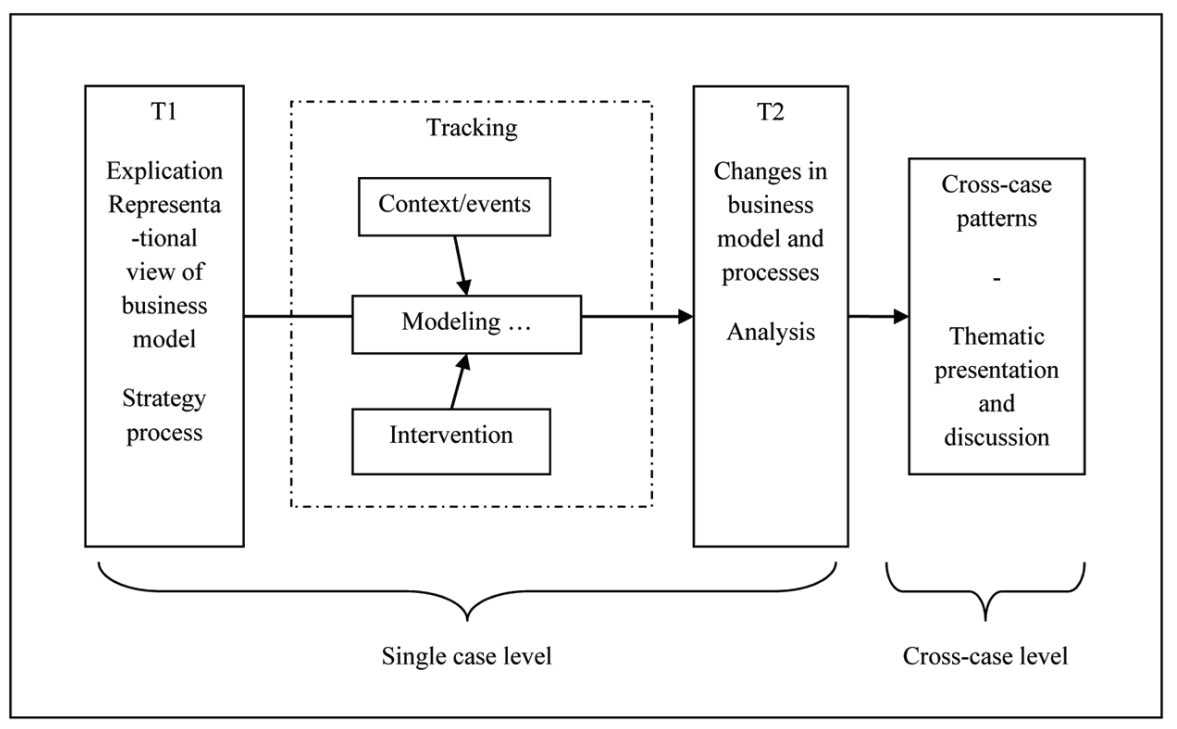

Figure 1 Conceptual map of research design. 


\section{Case Presentations}

The below table presents the case companies according to business area, geographical scope, ownership, year of foundation, number of employees, key informants and primary data sources.

All businesses had some kind of strategic plans and activities and an elaborated view of their current situation and challenges. The motivation for working with business models differed among the cases: Alpha was in the middle of a strategy process and wanted a simplification of its approach. Bravo was interested in developing a business model for its new services. Charlie had challenges of aligning expectations in the organization and wanted to take a fresh approach for substantiating the ambitions. Description of the individual cases follows.

\subsection{Company Alpha}

The core business of Alpha is steel and aluminum constructions. The company was established in 1984. There was a shift of owners in 1999 and (partly) again in 2011. The company produces to order and works as a regional supplier, primarily. The company is composed of three complementing companies, which in combination can provide a total solution from technical specifications, steel and aluminum cutting, welding as well as installation. The company employs about 45 people.

The company has a tradition of running dynamic, regular 3 year plans and revisions to guide its actions as this enables transparency of what is going on. This process has been driven by management and included the board as well as the employees. In addition to formal, text based documents, the values and strategies have been communicated in various ways, such as paintings which are hanging on the company's premises. The management group is dominated by technical education and experience and consists of the CEO, a technical manager, and the younger partner.

In 2009 management had to deviate from the traditional management style, following a dramatic drop in activity due to the impact of the global financial crisis. Consequently, Alpha reduced manning, cancelled strategic initiatives and went into a day to day management mode. In late 2011 the situation stabilized and management made a mental decision to "cancel" the crisis. In this connection the company hired a new manager (partner) and initiated a strategy process, with a new range of activities aiming at positioning the company closer to the customers, target new markets, and include more services. This process resulted in a text rich document which management 
Business Modelling as a Way Forward for Strategic Management Processes 9

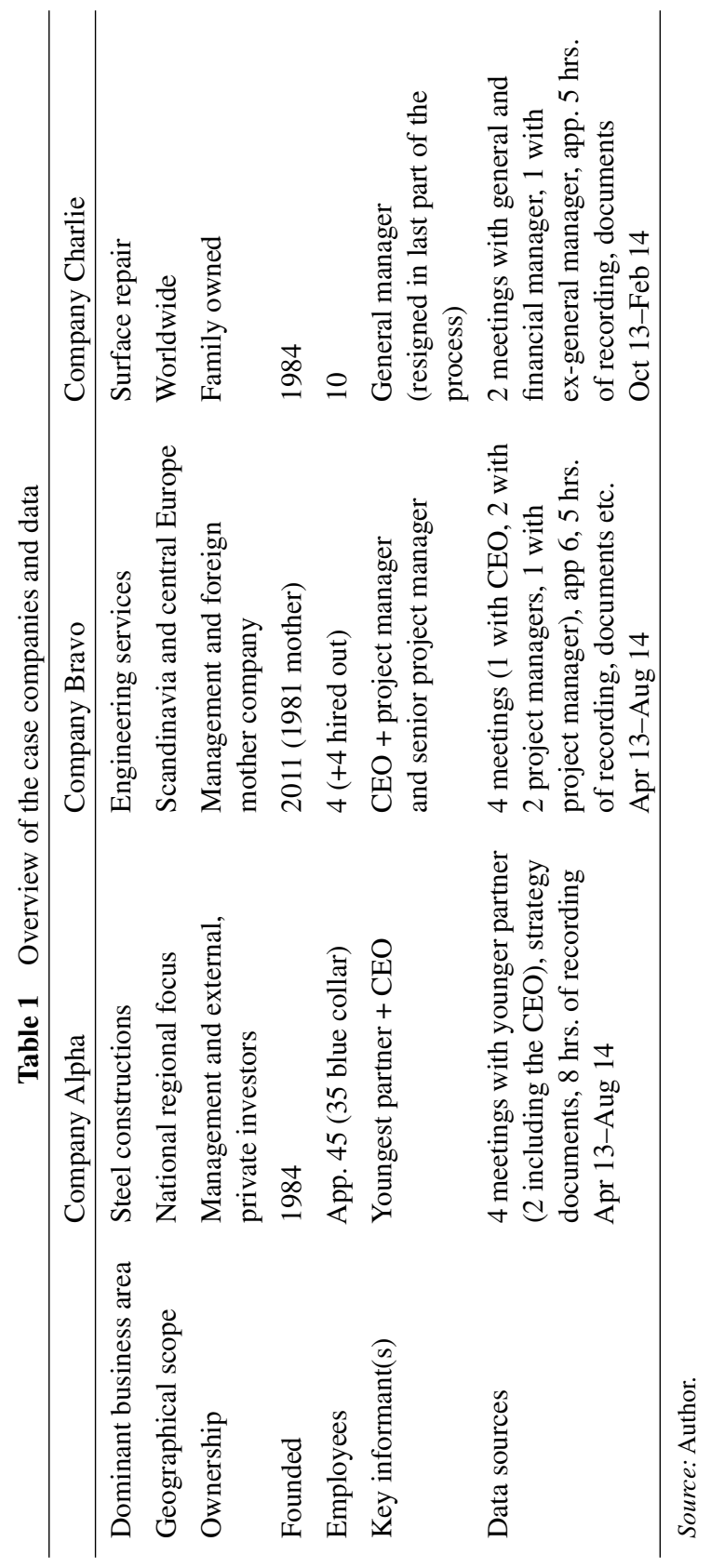


felt needed a simpler structure to provide a better overview and basis for discussion within the management group as well as the board and employees.

The connection between the company and the researcher was established in the early spring of 2013. In the first meeting the canvas was presented and served to structure part of the discussion. Different ways of applying the concept was discussed. The company immediately grasped the idea. Within a week Alpha managed to depict its business model in the canvas. At this point, however, there was a kind of mental "lock in" to the graphic representation. The question "so what?" appeared. The researcher intervened with a suggestion to change the format of the canvas-map to a table format, in a spreadsheet. The table format allows the integration of already existing material in the managerial structure, thereby adding a dynamic dimension. This include a swot (strengths, weaknesses, opportunities, threats) analysis as well as scenarios of future ("to be") business models, thereby adding a dynamic dimension to the canvas. This format has enabled management to include and adapt existing plans to encounter the opportunities and threats. As a further benefit, it has been possible to assign organizational responsibilities. As a result, the business model has been adapted in the management of the company. It is hanging on a white board in a meeting room and updated when needed. The business model has also been presented and discussed with the board as well as the remaining organization. Over time the business model has developed and its content has become much richer than in the beginning.

The modeling process also led to the discussion of two issues. The first was the strategy horizon for the future business model, as a total, and in the different areas of the business model. As a consequence the strategy horizon of e.g. areas of competence development and HR was expanded. In the later part of the research period, upgrading and investments in new machinery was included in the business plan. A second issue was a discussion whether Alpha had one or more business models due to the presence of a subsidiary which has its own customers. So far the company see it self as having one business model, i.e. the role of the sister companies are complementary and integrated.

At the end of the research project the company is thriving although the development does not fully live up to the ambitions. The company has achieved certificates which enable it to enter new segments. It has also made new relations with other companies to strengthen and complement its resources and value proposition. It has also received the first orders from a new geographic market.

The effects of the business model explication and application is primarily related to the management group. The younger partner has been a driving 
force in a quite consistent application of the concept in this group. There have been two regular strategy audits with the business model as a basic element of these discussions. As a result, the business model concept is effectively integrated in the management practice. It is a living construct as components and activities are upgraded or replaced, reflecting new and more relevant issues. This also means that the general business model canvas is becoming less and less traceable.

\subsection{Company Bravo}

Bravo is an engineering company founded only few years ago by a manager returning from an international position in the mother company which also has the majority of the ownership. The company offers engineering services on a project basis. Customers are primarily big companies in the offshore oil, gas and wind energy industry and naval architecture. The company operates on a stand-alone basis, but some projects are solved in cooperation with the mother company.

The initial contact was established with the CEO during in the early spring of 2013. Major topics in the first meeting were the general business model, selected projects and activities with other firms. The CEO (an engineer by education) had a quite elaborated understanding of what a business model is, but wanted to explore it more thoroughly after the presentation of the general business model canvas.

As a first step it was decided to focus on a new service related to ship energy efficiency. This topic is very hot in the industry due to the (then) strong increase in fuel prices, as well as future legislation on emissions. The current business model of this emergent service was mapped in the canvas in August 2013. This meeting involved a project manager and the senior project manager in charge of the specific service area. A major point in the discussion was the relation between the traditional business model and the new service. The initial model was very much in line with the general (consulting) model of the company. Different alternatives were discussed in the light of the expected development of the market, the customers, the competitors, the available resources and potential revenues.

In October 2013 the project manager of the company received training on business modeling. During, and after this, the company worked on a business model canvas for their existing activities as well. This model was discussed and modified through the involvement of the employees. A third meeting with the company in February 2014 was dedicated to a general follow up 
and sharing of experience. The strengths and weaknesses of the business model canvas were evaluated. In general the project managers were very happy with the process so far. Major contributions were related to providing an overview and shared picture of the situation, for discussing different issues and the involvement of the employees. Some of the points missing were the dynamics, including the future oriented initiatives. The leading project manager, in particular, was asking for more structure in this area and a link to other tools. Consequently, different strategy and managerial tools from the company were reviewed during this meeting (budgets, swot, customer statistics, project pipeline, mission statements, the relation to the mother company and the board etc.). The researcher suggested the possible integration of these in the business model (in line with the interventions in the Alpha case). These ideas were partly adapted.

After the meeting, however, other events in the company distracted further work on this. The senior project manager of the new service left for a related position in a much larger company, leaving this business area in a temporary vacuum. In June 2014 the company announced a merger. At a fourth meeting with the company in August 2014 the project manager expressed that the need for further work on the business model and structuration had not decreased but practical issues of the merger and integration had taken most of the resources available. The differences and similarities between the business models of the two merging companies were discussed.

So far the business modeling process in Bravo had been centered on management and employees. The scalability and the immediate simplicity of the model has enabled "non-strategists" to discuss strategic issues based on a shared model of the firm. Further integration was possible but the resources were allocated for the merger. The discussion of integration also revealed a need to supplement with "missing" elements of context and dynamics of mission/vision.

\subsection{Company Charlie}

Charlie is a company providing surface repair kits to the maritime sector. Products are manufactured by a supplier and the company sells them globally and advises on their application. The company was established in 1984 by its current owner, who is formally also the CEO. Daily operations are in the hands of a general manager, who has been the main driver of the strategy processes and the main contact during the research. The board consists of three people, two external members and the CEO. 
The founder of the company has a strong entrepreneurial profile with an emphasis on sales. He has very ambitious growth targets for the company. The general manager is an MBA by education and has been in charge of the company since 2011 after a career in an international industrial company. In this period the general manager has been working on establishing a strategy process involving the board and the employees. For motivational and organizational reasons the general managers sees a major need to substantiate the ambitious growth objectives. There have been a couple of attempts to identify and substantiate such a growth path but for various reasons this has failed. A recent reason was the challenging environment resulting in sudden slowdown of sales in 2012, which meant a reduction in manning. Charlie has, however, competitive products and a healthy financial situation.

Charlie learned about the business model from a network meeting in which Alpha was present. This resulted in a dialogue between the management of the company and the researcher in September 2013. At this time the general manager was again trying to define its future strategy, but management felt dissatisfied with some of the models in play. This included well known concepts such as the 7S framework models, "big bang" models, generic strategies, the value chain, the "hot spot model" etc. A major problem was the nature of these models, which were too abstract, too complex or incomplete and generally difficult to communicate in the limited time available.

In an attempt to break new ground and facilitate progress the business model concept was applied. The depiction of the current business model was done fast by the company itself. At this point, however, the process reached a point of stagnation. The feeling was an absence of future orientation. After sharing experience with Alpha and a meeting with the researcher in October 2013 , this process was restarted. The approach was similar to that of Alpha and Bravo; change the format of the business model to a table-based spreadsheet model. The swot model was included in the model. A formal process involving the organization and the board was established. The organization was involved in relatively short sessions addressing selected topics (e.g. sales, marketing, and channels) of the business model. Each session was limited to $1 \mathrm{hr}$, , but more sessions were possible for each topic. The purposes of the sessions were to generate facts, objectives and options for activities. This process revealed additional needs of information, such as a deeper understanding of the actual performance of the company's products (its value proposition), new segments, potential conflicts in distribution channels and possible risks.

In the process, the original canvas was gradually changed into a more company specific model through further decomposition and changes of terms 
and labels. A financial simulation model was developed simultaneously. This enabled management to describe and compare possible, future ("to be") models with the current ("as is") model to identify the major gaps. One future business model was presented to the board (March 2014), including the major gaps to be closed to realize this model. The board approved this approach and the next decision point of preparing a 3 year plan. Eventually, the organization was engaged in preparing this plan.

At this point (April 2014), however, the general manager decided to resign following some disagreements with the owner. These disagreements were not related to the business modeling process or the performance of the company, which at this time was according to plan. Consequently, the owner decided to take charge for a period, which has led to the roll back of some of the initiatives due to a different management style. The former general manager is, however, enthusiastic about the results of the process and continues to work with the business model concepts in a new position.

\section{Case Analysis and Theoretical Discussion}

This section will specifically analyze the cases supplemented with theoretical reflections in order to address if - and - to which extent - the business model concept can facilitate the strategic development in small and medium sized companies. The discussion is organized thematically, linked to the cases and aims to extend beyond the current sample. The themes are: Business model and value creation/capture; templates and process; the organization and the business model; actors matter; the conceptual business model logics.

\subsection{Business Modelling and Value Creation/Capture}

Value creation and value capture are essential dimensions in the business model concept. Theoretically, it is argued that business models are able to embrace innovative activities and several sources of value. All case companies were well established and "going concerns", i.e. facing no immediate threats, but operating in a perceived transition mode under a "growth" theme. However, the business model concept had to embrace important variations of growth and changes during the process: Alpha was planning by extending its current business model into the future and new markets, eventually leading to the inclusion of longer term issues (e.g. related to competencies and human resources) in its plan. In Bravo by simultaneous service/product development and market penetration with a process divided between the existing business 
model of the current, dominant business and the emergent business. The discussion was oriented towards whether a different "value logic" would create a bigger value creation and capture for a new service. This topic was also touched upon in Alpha. For Charlie the challenge was to identify how a future, very ambitious, state of the business could be bridged with the current state, i.e. to identify and decide on possible road maps.

From a process perspective it is interesting to note the changes during the process. The "filling-out the canvas" exercise in the first phases focused attention towards "holes" in the current strategy (empty fields in the canvas). This process also led to the framing, re-interpretation and reframing of existing knowledge. However, early stage business modeling apparently consolidated the current business model and did not incur any questions to the logic of the existing business model or further ideas for innovation. It is, however, encouraging that only minor interventions, such as questions, examples and ideas, are required to stimulate such thinking (although practical implementation may be a different issue). In Alpha inquiring about the time horizon raised new issues related to resources. In Bravo there were discussions of different ways to capitalize on the services offered. In Charlie positioning of the business model and extension models (such as industrial franchising) was discussed. In addition, the case companies were mainly customer oriented, i.e. focusing on value propositions, customer relations and market growth. Terms such as "competitive advantage" or competitors were not the main topics for discussion. The canvas seems to emphasize a company-centric perspective.

From a theoretical perspective the company behavior may be perceived as trying to approach and solve what is the "easy", identifiable and manageable (tamed) problems whereas more complex (wicked) problems [46] are not addressed. As such the application of the business model concept seems to some extent to follow a path of least resistance and quick wins, which create short term process value. As empirical studies show, this may be a rational choice, leading to low risk gains $[47,48]$. Research by Lindgren [49] indicates that firms are only using a limited range of the possible ways of innovating, thereby not realizing the full potential. These findings raise the question of how to set the appropriate level of ambition.

The evidence here supports the notion of the business model as a platform of learning [Chesbrough, quoted in 50] as a dynamic backbone and integrative platform for strategic initiatives. In this way partial analysis or solutions which require special approaches can be integrated in the business model. As such a richer and richer model can be developed as learning is accumulated. However, keeping the process alive and regularly challenging the current 
version of the business model seems important to counter institutionalization of the model and process (theories in use). This may be facilitated by using the general, universal, framework as a reference ("mirror") in an annual systematic strategy audit, thereby building virtuous planning cycles, in contrast to shifting to new theories and frameworks requiring time and resources for learning. The innovativeness and learning potential may be restricted, however: In an experimental study of artefacts and innovation Eppler, Hoffmann [51] showed that using the business model canvas significantly increases perceived collaboration but decreases perceived creativity. It remains unclear whether another framework e.g. activity maps [23], or white spaces, [52] may direct attention to competitive advantage based on positioning, resources or innovation in general. We need more research on how businesses identify and assess "valuable problems" [53, 54], the effects of managerial ambitions, and the repertoire of managerial tools for doing so.

\subsection{Templates and Processes}

Not surprisingly, the format and content of a framework attracts the attention of its audience. It is therefore important that it represents the "right" issues and works well during the whole process in order not to lead in wrong directions or create frustrations. Models and frameworks, including the canvas, are imperfect abstractions of reality, being more or less incomplete, biased and silent on specific issues [55]. Following the pragmatic view of this project, we are here concerned about practitioners' experience of the canvas.

Identification of the business model(s): A practical question of applying the canvas was to define whether the companies had one or more business models? In practice businesses develops over time and current business models are reflecting past decisions, current practices and aspirational future. Some segments/products are being phased out; others are in a growth phase. As a result the depicted business model has "fuzzy edges". This challenges the analytical mind and the "logic" dimension of the business model definition. The practical way of dealing with this issue was to concentrate on what was perceived as the "dominant" business model. In different contexts this may not be sufficient; e.g. defining the right unit of strategizing may be critical in the case of transition from one business model to another.

Adaptation: The business model idea was welcomed and provided new energy to the strategy process. The initial, low learning barriers were quickly overcome and the companies were quick to depict a first version of their 
business models in the canvas. The business model concept was clearly compatible with, and in fact increased the value of, already existing material and concepts which was incorporated into the business model. This was clearly seen in case Alpha, where the essence of a 15-20 pages strategy document and several additional documents could be depicted in one A3 format. As a further example, the combination of the canvas and the popular swot analysis overcomes the typical weaknesses of swots for being too subjective and lacking an anchor. The adaption process also meant that the generic framework was internalized and changed (particularly in Alpha and Charlie) as the generic business model components and terms were changed to "company language", e.g. by specifying "customer relations" in existing and future customers, resources" to "human resources" and "machinery".

Dynamics: In all cases it was clear that the pure depiction of the business in the canvas didn't provide much progress. Having written a finished canvas created a "what's next" feeling. A dynamic aspect was missing and there was a "lock in" to the graphic representation. Two important elements were missing to make the process engaging and dynamic; management ambition and context. These elements may be added in two ways: Either by complementary tools applied in the process, or by adding new components to ("repairing") the business model canvas. In the specific cases this was solved by changing from a "picture" to a table format, adding a SWOT to the canvas, and changing the label of some of the business model components to a company idiosyncratic language (case Alpha and Charlie). Additionally, "soft" issues such as mission, vision, and values were clearly important and discussed in the process (case Alpha, Bravo, Charlie). Freytag and Clarke [56] suggest that context and visions are explicitly added to the canvas. Other conceptualizations of business models already include these dimensions [57, 58]. Basically this reflects an early discussion whether strategy is part of the business model or not. An inclusion seems less relevant for a static, representational, fact oriented view, but it is clearly more important for a process view on modeling.

\subsection{A Link between the Organization and the Business Model}

The cases demonstrate how business models can be linked to the organization, thus addressing the question as to who has the responsibility for the business model. This may embrace cognitive and formal aspects of organizational life reflecting several views on business models. Inclusion of employees, for capturing relevant ideas and taking ownership for the strategy were 
important considerations in the cases. This applied for both the day to day management, but also in the communication with the board and the employees. The following discussion focuses on two types of alignment and the link between the business models.

Alignment: Organizational alignment can be seen from a horizontal as well as a vertical perspective. The vertical perspective is the hierarchical structure of the organization, here; daily management, board level and operational level. The horizontal perspective addresses the individual levels. In the cases the business model canvas was introduced at the daily management level, providing a shared picture of the business. In all companies senior management applied the canvas at the operational level (although it may be argued that the organizations are small, with an overlap between daily management and operational level). In Alpha and Charlie it was also an ambition to apply the business model canvas at the board level. In Alpha this took place in a "weak" form due to other pressing issues. In Charlie this was limited to the analytical phase and first milestone decisions due to shift in management. Basically this addresses traditional challenges of linking strategic thinking with activities at the operational level through the different levels of the governance chain (cascade models). At the operational level employees can see "the big picture", they can contribute to the strategy process, and they can know their role in implementing the strategy. At the managerial and board level it assist in maintaining a coherent and holistic view of the business as well as assigning organizational responsibilities. At the board level it provides transparency (for external directors having a distance to day to day operations).

Linking the business model and the governance model: Business models are embedded in existing managerial practices, such as strategy processes, budget and follow up systems, project plans, board material etc., which in broad terms are related to the holistic governance of the company [59]. Although part of this have to comply with formal legislation there are possibilities of integration with the business model in a systematized, ex ante oriented perspective which increases transparency. For instance, financial metrics have a significant influence on investment decisions and outcomes [52, 60, 61]. Further empirical research on such a forward oriented approach may enhance our understanding of best practice business modeling. This may ensure that activities rooted in the holistic perspective of the business model and are contributing to the aims of the business and its legitimate stakeholders. It may also add new dimensions of governance by integrate culturally and value 
based forms of governance with formalized structures to create self-governing systems (autopoesis).

The organizational alignment and governance perspective deserves more attention, and may be conceptually supported by the literature of seeing business models as a result of strategic and tactic decisions or result of different "levels" of practices [23 and 58]. A general, applied and prescriptive approach is found in Wirtz [62].

The organizational involvement in the business modeling process of each case is summarized in Figure 2.

\subsection{Actors Matters}

Like any other change business model development is dependent on an "entrepreneurial force" from one or a group of actors. In the cases there was an influential actor with strong interest in the business modelling process, pursuing some kind of value from the process. The actor dependency became particularly clear in Charlie where the general manager resigned and the process was halted. The entrepreneurial and change oriented literature explicitly elaborate on the role of the "change agent", whereas the individual agent has somehow been "lost" in some of the strategy perspectives [29, 31]. In combination this draws our attention to the role of the actors.

The creative force of actors: In the actors view of the world reality is disintegrated. The academic community often applies reductionist and partial

\begin{tabular}{|c|c|c|c|}
\hline & Case Alpha & Case Bravo & Case Charlie \\
\hline Board & $\begin{array}{l}\text { Brief } \\
\text { presentation } \\
\text { to the board }\end{array}$ & None & $\begin{array}{l}\text { Business model presented } \\
\text { for basic decisions } \\
\text { (process halted) }\end{array}$ \\
\hline $\begin{array}{c}\text { Senior } \\
\text { management }\end{array}$ & $\begin{array}{l}\text { Integration of prior } \\
\text { analyses and plans } \\
\text { as well as follow up }\end{array}$ & $\begin{array}{c}\text { Limited integration } \\
\text { of analysis }\end{array}$ & $\begin{array}{l}\text { Integration of } \\
\text { analyses and plans }\end{array}$ \\
\hline $\begin{array}{l}\text { Operational } \\
\text { organization }\end{array}$ & $\begin{array}{l}\text { Communication } \\
\text { with and } \\
\text { involvement of } \\
\text { employees }\end{array}$ & $\begin{array}{l}\text { Involvement of } \\
\text { employees }\end{array}$ & $\begin{array}{l}\text { Intense: Sessions } \\
\text { of fact gathering } \\
\text { and discussions, } \\
\text { scenarios }\end{array}$ \\
\hline
\end{tabular}

Figure 2 Business model and organizational involvement. 
analysis to understand and explain phenomena. Practicing managers may use similar techniques for analytical purposes, but need integration in order to be able to act. Four elements have to be in place for enabling an actor to act [63]: 1) Facts - which are needed for connecting with reality and make predictable assumptions about what works and what not works. 2) Possibilities for acting. Realistic possibilities based on facts and logical reflections. Since there are endless options for combining facts, this implies construction of and choice among the options. 3) Values are needed to mobilize energy and to realize possibilities. In the actor perspective the strongest motivational force to act is an intrinsic satisfaction from creation. 4) A necessary integration of facts, possibilities and values in one construct, so "that the possibilities are factual and so that the values are possible" [63]. There is "not one "true" integration, but always many possible solutions to integrate problems" [ibid]. 5) The final necessity, communication, is related to groups of actors, such as organizations, in which communication needs to be added as necessary "for coordinated integration, i.e. communication must itself be integrated with the facts, possibilities and values" [ibid]. To be truly actor based, the company integration of facts, logic, values and communication should be coherent with the involved actors' subjective integration. If the connection between the individual and the organizational level is absent possibilities will be abstract speculations. One way to define management is "to create results via the actions of others". Many organizations rely on the creative force of their employees at all levels. This requires the initiatives and actions of the employees through involvement in all stages from development to implementation. In this way organizational actors are co-authoring, i.e. co-modelling, the business.

Business modelling and creative actors: The actors view provides us with interesting insights from the evidence on business model and the forces of their dynamics: In the actors view the canvas equals the facts, as it is a representational view, i.e. the unit of analysis of the current business model. This "fact" view could not stand alone, and the actors lacked perspective (the "so what" feeling) and asked questions. Actors in the case companies intuitively requested integration with mission and vision (possible futures and values). The canvas, at least in the form applied in the cases, exhibited robustness in the ability to link to the future possibilities - i.e. the connection between facts of analysis and facts related to the possibilities. Initially, the possibilities were closely connected to the current facts, i.e. bound to the current model, but soft intervention could quite easily push the borders to generate other possibilities. The business model - incorporating its many 
dimensions and perspectives - is applicable as a media for this integration even on a dynamic basis. However, the business model canvas (like other general models) in its generic format is imperfect for representing the business model of the specific company: Imperfections in the canvas were directed, terms were relabeled and further categories were developed. The general format facilitated the re-integration of the current specific model, into a new specific model. From a pragmatic point of judgment, i.e. "value in use", this format must have been better than the old one. At times, depending on circumstances, re-integration, is necessary due to better insights into one's own awareness of facts and possibilities as well as changes in the environment. Hence, the scale of the re-integration may vary: In the case companies not all components of the business model was attracting equal attention in the adaption process which, naturally, reflected priorities and interests at that time. At the more general level, this process is influenced by cognition, awareness and knowledge of the actors.

Perspectives: The evidence demonstrates that for practical purposes business models and similar conceptualizations which are holistic and easy understandable may 1) facilitate the integration and communication in particular, or 2) point to problems of integration, as the exposed challenges between the current realities and growth ambitions in case Charlie. A representational view, however, cannot stand on its own - it has to be complemented with a process, which may be guided more or less tight, and may enforce the existing or open new business model opportunities. Apparently the business model canvas offers - consistent with an actor's perspective - a construct which integrates facts, possibilities, values and communication in order to enable action for the individual as well as the group. This has a process value: Simple, but efficient management tools may reduce managerial complexity so that time could be used for discussing substance of business importance rather than technicalities of combining and applying advanced models. Although the processes may differ, this may have value both for both new and established business models [33]. For companies it may reduce the "dip" in the initial performance before the benefits of implementing a new process can be harvested (the "J"-curve).

If the dynamic process benefits of reflection and communication should be maintained over time, it seems important that the business models doesn't develop into static, mechanic forms which restrict reflection: "The need is to create the media of ongoing dynamics of conceptualization which itself controls and develops the systems according to need and thus enables the 
company to develop" [63]. This emphasizes the role of business models as units of strategizing but in particular as a dynamic construct. More broadly this could contribute to a better understanding of strategy and the dynamics between "prescriptive" formats, managerial practices, values, the embedded business model and processes in companies. It may provide insights if there are special capabilities [64] or "flows" which supports the ongoing development of companies. In continuation, it may be argued that strategic and managerial processes are complex, dynamic and unpredictable, requiring different skills and maybe different personalities extending beyond the capacity of single individuals, i.e. there may be no perfect leader for all seasons [65]. Following this, an interesting question for further investigation would be to assess group dynamics in management teams during business modeling.

\subsection{The Business Model Conceptual Definition and "Logics"}

As already described practitioners were questioning how to define and delimit the business model. In practice, this was solved by focusing activities which constituted the current or potential dominant share of the sales of the firm. The resulting business model could be perceived as consisting of a dominant core with fuzzy edges. Consequently, the case companies began, and continued to emphasize value proposition and customer components. As already stated this is very traditional and doesn't exploit the full range of options in e.g. the network dimensions. Maybe for this reason the practical application of business models is often highly firm centered, as in the cases and in the business model literature.

The conceptual definition potentially connects to several possible, basic sources of economic rent related to the different components, but these links are not clear and for this reason they may be partly ignored due to the difficulty of analyzing them. Whereas the value dimensions, the network and focal company may be ambiguous terms they have been discussed in the literature from different disciplines. The logic dimension appears less elaborated and probably more complex. This aspect may benefit from more attention. The representational view and a mapping process may identify components, the causality between the components, and emphasizes a business model understanding as a "design or architecture of the value creation, delivery, and capture mechanisms" [66]. This design perspective is also stressed by Osterwalder [21]. There is, however, a risk that the business model becomes a "surface description", a simple list and description of the business model components, without capturing the dynamic and underlying logic, i.e. the systemic aspect, 
of the business model. Even if it does, "objective" and representational views may miss the motivation to drive change. For managerial, pragmatic, purposes the inclusion of possibilities and desires to provide direction requires more dimensions. This imperfection could point in the direction of the existence of a "bigger" concept or meta model [67] for business models to work.

The "logic" dimension of the business model may be perceived as a higher order construct, than the equal weighting in the wording in the definition indicates; "logics" being the determining and underlying concept of understanding the nature and background for the business model in various contexts. The logic connects and ensures the coherence of the business model components across its dimensions, its levels, and the boundaries between the business, the environment, organizational borders and it has a dynamic element related to the strategy and contextual influences. Similarly, incoherence and inconsistencies in the logic results in performance challenges, frustrations and the repulsion of apparent alien and dangerous activities. It is not clear, however, if and how the logic dimension relates to narratives, legitimate and recipes. The closest approach may be that of Morris, Schindehutte [58] suggesting a connection between a foundational, a proprietary and a rules level for the different components. Similarly, Casadesus-Masanell and Ricart [23] distinguishes between different levels, i.e. strategic, tactic and operations. It has been suggested that business models can be seen as performative representations embracing "transactional structures, value extracting devices and mechanisms for structuring and guiding the organization" and which articulates "narratives that persuades, typifications that legitimate, and as recipes that instruct" [68]. There is a need for further empirical research and understanding of these aspects.

One avenue on further research on the logic aspect is to bridge to the established research of "dominant logic" [69, 70]. Empirically, this type of research is often connected with cognitive mapping methods, the leadership/management and decision literature. Tikkanen, Lamberg [71] has modeled the relationship between cognition and business models, and possible implications regarding the boundaries of the firm and product development. The same approach has been applied to understand the success and failure of Nokia [72]. Further work in this area may contribute to our understanding of business models, what they are, and their dynamics. In practice, facilitation may be important for the actual modeling process and may potentially be divided in several stages; initially aimed at capturing and describing the logic, to later stages inquiring into and questioning the logic with respect to the context, ambitions etc. of management. 


\section{Synthesis: Different Strategy Roles of the Business Model Concept}

This section aims at summarizing the discussion through a synthesis, based on three possible and distinctive roles of the business model concept providing an explicit linkage to strategic purposes and roles of; 1) development, 2 ) innovation, and 3) alignment. These different roles have implications for the logic of and the process of business modeling.

A substantial part of the extant literature on business models focuses on the innovation and development of business models, emphasizing creativity and change in different contexts and degrees of "new" and "existing". The distinction between business model development and business model innovation, although present in the literature for some time, has very recently been more explicitly addressed by Massa and Tucci [33] and Ahokangas and Myllykoski [34]. This literature emphasizes the processes of creation and change as different types of activities. The empirical results of this present study elaborate a third and important role of business models: Alignment. Alignment emphasizes understanding, coherence and joint efforts. Alignment increases the transparency, improves performance and the ability to control risks and systematize learning. Alignment does not mean that business models are stable or unchanged. Rather, alignment implies an ongoing and dynamic adjustment of the business model. Alignment however, is relative and needs an anchor; what is going to be aligned to what? In the Alpha case the alignment was clearly oriented towards the current business model. In the Beta case the situation was a bit more complex: There was a tendency of the new initiative to become aligned with the current dominant business model, with only limited examination of potentially stronger business models. Alignment may therefore enforce existing models, but it can also provide barriers to new models. In Charlie the efforts were aimed at describing a future business model and align the current and potential activities towards this. Lack of alignment caused frustration and potential lack of progress in the development. In general, the alignment role seems particularly important for the operational performance of current business models and for coordinating and aligning efforts for changes to the business model. The alignment role may therefore be seen as an independent role or in connection with the development or the innovation role; alignment may be a necessary antecedent to facilitating change or innovation as well as necessary and basic step in the implementation of new initiatives. 
The empirically based elaboration of the alignment role is consistent with other findings in the literature as it connects well with the early idea of change models suggested by Linder and Cantrell [73]. The notion here is that business model change takes place within a "change model" consisting of a coherent set of ideas and actions, which are internally and externally consistent (i.e. aligned) and aimed at improving the competitiveness. They distinguish between 4 types of change models; 1) realization models, i.e. optimization of the current model, 2) renewal models to maintain competitiveness of the current model 3) extension models, stretching of the current business model e.g. into new markets or technologies; and 4) journey models which implies the change to a new business model. The alignment perspective also connects with the evolutionary perspective of Morris, Schindehutte [58] visioning a business model life cycle as composed by "periods of specification, refinement, adaptation, revision, and reformulation". Alignment may have different orientation and take different forms in each of these "periods" and crossing from one to another may have implications. As Cavalcante, Kesting [74] states: business models can only be flexible to a certain point. They distinguish between 1) business model creation, 2) business model extension, 3) business model revision, and 4) business model termination. Similarly, Sosna, Trevinyo-Rodríguez [75] explained the development of a case as a learning journey with distinct phases of exploration and exploitation in which there is simultaneous emphasis on consistency and dynamics. While the existing literature can be applied to further expand on the alignment role, the specific contribution of this particular empirical study has been to emphasize and elaborate the value and challenges of doing so, as a specific result of explicating the business model. More detailed assessment of specific strategic purposes and contexts may contribute to more prescriptive approaches of business modeling.

Table 2 illustrates the three roles and differences on selected parameters. The different roles are linked to different purposes and contexts of the strategy process. The purpose of the strategy process may target development needs to the existing business model. If relevant, the activities may be more innovative and address new areas which have path breaking implications in e.g. technology, markets, value propositions or similar. The different strategic purposes are therefore related to the logic dimension, but in different ways. Despite the clarification need of the logic dimension, it is possible meaningfully to address the nature of the changes to the business model in the three different roles. In the developmental role the current business logic is the basis for the development. In the innovation role, the current logic is being challenged - or new logics are 
Table 2 The link between purpose of strategy and the role of business models

\begin{tabular}{|c|c|c|c|}
\hline Role of bm > & Development & Innovation & Alignment \\
\hline $\begin{array}{l}\text { Link to strategic } \\
\text { purpose }\end{array}$ & $\begin{array}{l}\text { Current direction and } \\
\text { challenges - e.g. fine } \\
\text { tuning, extension/ } \\
\text { scaling }\end{array}$ & $\begin{array}{l}\text { New direction and } \\
\text { ideas e.g. new value } \\
\text { propositions, } \\
\text { business areas }\end{array}$ & $\begin{array}{l}\text { Improve operational } \\
\text { performance and/or } \\
\text { implementation }\end{array}$ \\
\hline $\begin{array}{l}\text { Relation to current } \\
\text { logic }\end{array}$ & $\begin{array}{l}\text { Development based } \\
\text { on current logic }\end{array}$ & $\begin{array}{l}\text { New ideas relative } \\
\text { to existing logic }\end{array}$ & $\begin{array}{l}\text { Enforce current } \\
\text { business model logic } \\
\text { or align change model }\end{array}$ \\
\hline $\begin{array}{l}\text { Process and } \\
\text { facilitation }\end{array}$ & Analytic-synthesis & Creative & $\begin{array}{l}\text { Dialogical/systemic } \\
\text { relations }\end{array}$ \\
\hline $\begin{array}{l}\text { Tools and } \\
\text { techniques } \\
\text { (examples) }\end{array}$ & $\begin{array}{l}\text { Frameworks for } \\
\text { identifying and } \\
\text { assessing new } \\
\text { opportunities, gap } \\
\text { analysis etc. }\end{array}$ & $\begin{array}{l}\text { Creative ideas abt. } \\
\text { new and major } \\
\text { changes } \\
\text { Experiments to test } \\
\text { relevance of new } \\
\text { value propositions } \\
\text { and logics. Risk } \\
\text { management. } \\
\text { Knowledge creation }\end{array}$ & $\begin{array}{l}\text { Common and } \\
\text { individual } \\
\text { understanding of the } \\
\text { defined business } \\
\text { model(s) and change } \\
\text { Conflicts and/or } \\
\text { integration with } \\
\text { existing plans and } \\
\text { processes, resource } \\
\text { allocation, priorities }\end{array}$ \\
\hline
\end{tabular}

being developed (and possibly compared to the existing). The alignment role of the business model emphasizes the coherence aspects of the operational and implementation aspects of the business model. At the actor level this addresses the previously discussed sense-making process at individual and team levels. It also relates to systemic aspects of the managerial control, cultural and structural properties of the organization. The different roles and purposes have clear implications for the process of the modeling of the business model and thus the appropriate tools, techniques and possible facilitation. Some examples are mentioned in the table. More research is needed for developing the role of alignment, including the potential benefits and challenges of explicating business models. Is there, for instance, an optimal point of explication of business models (suggesting an inverse $\mathrm{U}$ curve)?

More broadly, the different roles of the business model for different purposes relates to many themes and key questions which are familiar from the existing literature on business models, strategy, innovation and organization. Dedicated reviews may be important steps for consolidating the existing knowledge [see e.g. 33, 76] and thereby overcoming the challenges of increased fragmentation [e.g. 77]. The link to strategic purposes also raises 
the issue whether there are there any additional roles, related to other strategic purposes, which have not been adequately addressed by the literature. What is clear is that for managerial applications the connection between the strategic purpose and the subsequent role of the business model is an important link with implications for the process and the outcome.

\section{Limitations}

This discussion will focus on the method, the possibilities of generalization and possibilities of further research.

Major points of critique of a participative research approach are related to objectivity and bias, specifically the risk of the researcher going native, developing blind spots, and being actively promoting a specific method and point of view. As earlier mentioned the interventions in these cases have been quite limited (soft) and based on a constant assessment of when and how to intervene. This approach also implies the avoidance of involvement in conflicts (which were clearly present in some of the cases), which, on the other hand, raises the question if stronger/different results could have been obtained with more intervention and how these results would have benefitted different stakeholders. Equally, it can be asked what the process would have been if it had not been moderately influenced by an external actor and the influence of a framework, i.e. whether a different actor and model would create different results. Since these problems of objectivity and bias are unavoidable, it has been attempted to compensate by providing transparency of data, intervention and inference mechanism within the limited reporting space of the format of an article.

Another aspect is related to causality and the contexts of e.g. time and industry and the type of knowledge created. The situation is developing all the time as a result of actors' initiatives, external events and the impact of historical paths of the company. This raises the question as to when and how do we know if the business model concept works and in what ways? And are such developments comparable? This project has focused on bringing the business model out in the light and how this affects the strategy processes. The paper has been concluded at a point when (some of) the modeling effects on the strategy have been exposed. The actual business models have received less attention and it remains to be seen whether new solutions or better performance beyond processual benefits will incur in the longer term. A possible extension in time and scope could add significant dimensions of business output, i.e. actual 
changes in strategic position, new competitive bases and financial results compared to historic as well as industry related benchmarks.

In general, case studies are only valid for the specific contexts in which they are done and cannot be extended into general valid findings. What can be done, given time and resources, is to a) to extend the period of time, and b) include more cases of the big population of companies sharing the same characteristics as the case companies. The limitations of the findings may also be challenged by inclusion of bigger companies with a more formal and hierarchical management structure.

\section{Concluding Remarks and Perspectives}

This paper has investigated the in situ business modelling process of three case companies from a pragmatic perspective. The findings were discusses under the headlines of value creation/capture; templates and processes; organisation and business modelling; the role of actors; and the implications of logic in the conceptual definition of business models. The cases were analysed from a theoretical perspective and implications were discussed. The paper proposes that the variations in findings can be synthesized according to three different roles of the strategy process and the business model: 1) the developmental role, 2) the innovation role, and 3) the alignment role. Each of these three roles has different implications in relation to the underlying logic and process of business modelling.

From a pragmatic perspective the overall conclusion is that the companies benefited from the process. These positive findings may indicates that explicit business modelling may be a way forward for companies operating with the dilemma of the simultaneous need for flexibility, strategic direction and resource constraints. Initiating a strategy process with a relatively simple tool is superior to more complex strategy tools. Such modelling processes may suit particularly well as a way forward for small and medium sized companies trying to establish a strategic process. In short, companies need to find their own way instead of adapt and replicate practices of "big companies" which are unsuited to their contexts and resources. A bold proposition could be that continuous and agile modelling within a scalable business model conceptualization can enable consolidation and accumulation of learning which can lead to stronger strategic leadership than traditional and formal processes. 


\section{References}

[1] Drucker, P. (1954). The Practice of Management. New York, NY: Harper and Row Publishers.

[2] Dudik, E. M. (2000). Strategic Renaissance. New York, NY: American Management Association (AMACOM).

[3] Johnson, G., Scholes, K., and Whittington, R. (2010). Exploring strategy. 9 Edn. UK: FT/Prentice Hall.

[4] De Wit, B., and Meyer, R. (2010). Strategy: process, content, context. 4 Edn. Cengage Learning.

[5] Grant, R. M. (2010). Contemporary Strategy Analysis. 7 edn. New York, NY: Wiley.

[6] Kotter, J. P. (2012). Accelerate! (cover story). Harv. Bus. Rev. 90, 43-58.

[7] Bettis, R. A. (1991). "Strategic management and the straightjacket: an editorial essay," in Organization Science. INFORMS: Institute for Operations Research, 315-319.

[8] Mintzberg, H. (1987). The strategy concept I: five ps for strategy. Calif. Manage. Rev. 30, 11-24.

[9] Baden-Fuller, C., and Morgan, M. S. (2010). Business models as models. Long Range Place. 43, 156-171.

[10] Shafer, S. M., Smith, H. J., and Linder, J. C. (2005). The power of business models. Bus. Horiz. 48, 199-207.

[11] Zott, C., Amit, R., and Massa, L. (2011). The business model: recent developments and future research. J. Manag. 37, 1019-1042.

[12] Chesbrough, H. (2007). Business model innovation: it's not just about technology anymore. Strategy Leadersh. 35, 12-17.

[13] Doganova, L., and Eyquem-Renault, M. (2009). What do business models do? innovation devices in technology entrepreneurship. Res. Policy. 38, 1559-1570.

[14] Arend, R. J. (2013). The business model: present and future-beyond a skeumorph. Strateg. Organ. 11, 390-402.

[15] Zott, C., and Amit, R. (2013). The business model: a theoretically anchored robust construct for strategic analysis. Strateg. Organ. 11, 403-411.

[16] Amit, R., and Zott, C. (2001). Value creation in e-business. Strateg. Manag. J. 22, 493-520.

[17] Zott, C. and Amit, R. (2007). Business model design and the performance of entrepreneurial firms. Organ. Sci. 18, 181-199. 
[18] Chesbrough, H. and Rosenbloom, R. S. (2002). The role of the business model in capturing value from innovation: evidence from xerox corporation's technology spin-off companies. Ind. Corp. Change 11, $529-555$.

[19] Chesbrough, H. (2006). Open business models. Boston, MA: Harvard Business School Press.

[20] Zott, C., and Amit, R. (2010). Business model design: an activity system perspective. Long Range Plann. 43, 216-226.

[21] Osterwalder, A. (2004). "The business model ontology: A proposition in a design science approach," in Ecole de Hautes Etudes Commerciales. University de Lausanne, Lausanne.

[22] Chatterjee, S. (2013). Simple rules for designing business models. Calif. Manage. Rev. 55, 97-124.

[23] Casadesus-Masanell, R., and Ricart, J. E. (2010). From strategy to business models and onto tactics. Long Range Plann. 43, 195-215.

[24] Casadesus-Masanell, R., and Ricart, J. E. (2011). How to design a winning business model. Harv. Bus. Rev. 89, 100-107.

[25] Magretta, J. (2002). Why business models matter. Harv. Bus. Rev. 80, $86-92$.

[26] Verstraete, T., and Jouison-Lafitte, E. (2011). A conventionalist theory of the business model in the context of business creation for understanding organizational impetus. Manag. Int., 15, 109-124.

[27] Osterwalder, A., and Pigneur, Y. (2010). Business Model Generation. New Jersey, NJ: John Wiley \& Sons, Inc.

[28] Whittington, R. (2003). The work of strategizing and organizing: for a practice perspective. Strateg. Organ. 1, 117-125.

[29] Ericson, T., Melander, A., and Melin, L. (2001). "The role of the strategist," in Rethinking Strategy, eds H. W. Volberda and T. Elfring (London: Sage Publications, Ltd), 57-68.

[30] Johnson, G., Langley, A., Melin, L., and Whittington, R. (2007). Strategy as a Practice. Research Directions and Resources. Cambridge: Cambridge University Press.

[31] Powell, T. C. (2014). Strategic management and the person. Strateg. Organ. 12, 200-207.

[32] Pettigrew, A. M. (1992). The character and signficance of strategy process research. Strateg. Manag. J. 13, 5-16.

[33] Massa, L., and Tucci, C. L. (2014). "Business model innovation," in The Oxford Handbook of Innovation Management, eds M. Dodgson, D. M. Gann, and N. Phillips, forthcoming, (downloaded from http://www.businessmodelcommunity.com/\#Working_Papers.B). 
[34] Ahokangas, P., and Myllykoski, J. (2014). The practice of creating and transforming a business model. J. Bus. Models 2, 6-18.

[35] Cavalcante, S. (2011). A Process-Based View of Business Model Dynamics: An Explorative Study. Denmark: Aarhus School of Business.

[36] Eisenhardt, K. M. (1989). Building theories from case study research. Acad. Manage. Rev. 14, 532-550.

[37] Neergaard, H. (2010). Udvalgelse af cases $i$ kvalitative unders $\phi g e l s e r$. 2 Edn. Copenhagen: Samfundslitteratur.

[38] Yin, R. K. (2014). Case Study Research: Design and Methods. Thousand Oaks, CA: Sage.

[39] Coughlan, P., and Coughlan, D. (2002). Action research for operations management. Int. J. Operat. Product. Manag. 22, 220-240.

[40] Argyris, C., Putnam, R., and Smith, D. M. (1985). Action Science. San Francisco, CA: Jossey-Bass Inc.

[41] Dubois, A., and Gadde, L.-E. (2002). Systematic combining: an abductive approach to case research. J. Bus. Res. 55, 553-560.

[42] Dubois, A., and Gadde, L.-E. (2014). Systematic combining-A decade later. J. Bus. Res. 67, 1277-1284.

[43] Miles, M. B., Huberman, A. M. and Saldana, J. (2014). Qualitative Data Analysis: a Methods Sourcebook. 3 Edn. Thousand Oaks, CA: Sage publications, Inc.

[44] Gioia, D. A., Corley, K. G., and Hamilton, A. L. (2013). Seeking qualitative rigor in inductive research: notes on the gioia methodology. Organ. Res. Methods 16, 15-31.

[45] Stake, R. E. (1994). "Case studies," in Handbook of Qualitative Research, eds N. K. Denzin and Y. S. Lincoln, Thousand Oaks, CA: Sage.

[46] Freytag, P. V. and Philipsen, K. (2010). Challenges in theoretical building blocks and management implications, in challenges in relationship marketing, eds P. V. Freytag and K. Philipsen, Århus: academica.

[47] Adner, R. (2012). The Wide Lens. A New Strategy for Innovation. London: Penguin Group, Ltd.

[48] Zook, C. E. (2007). Finding Your Next Core Business. Boston, MA: Harvard Business Press.

[49] Lindgren, P. (2012). Business model innovation leadership: how do sme's strategically lead business model innovation? Int. J. Bus. Manag. 7, 53-66.

[50] Sandberg, K. D. (2002). Is it time to trade in your business model? Harv. Manag. Update 7, 3. 
[51] Eppler, M. J., Hoffmann, F., and Bresciani, S. (2011). New business models through collaborative idea generation. Int. J. Innov. Manag. 15, 1323-1341.

[52] Johnson, M. W. (2010). Seizing the White Space: Business Model Innovation for Growth and Renewal. Boston, MA: Harvard Business Press.

[53] Nickerson, J. A. and Zenger, T. R. (2004). A knowledge-based theory of the firm-the problem-solving perspective. Organ. Sci. 15, 617-632.

[54] Nickerson, J. A., Silverman, B. S. and Zenger, T. R. (2007). The 'problem' of creating and capturing value. Strateg. Organ. 5, 211-225.

[55] Rosenberg, A., Chase, G., Omar, R., Taylor, J., and von Rosing, M. (2011). Applying Real-World BPM in an SAP Environment. SAP Press.

[56] Freytag, P. V. and Clarke, A. H. (2012). What are We? Where are We Heading? On Changes in the Understanding and Role of Advertising Agents. Denmark: University of Southern Denmark.

[57] Stähler, P. (2002). Geschäftsmodelle in der digitalen Ökonomie. 2 Edn. Zürich: Eul Verlag.

[58] Morris, M., Schindehutte, M., and Allen, J. (2005). The entrepreneur's business model: toward a unified perspective. J. Bus. Res. 58, 726-735.

[59] Johnson, G., Whittington, R., Scholes, K., Angwin, D., Regnér, P. (2014). Exploring Strategy - Text and Cases. 10 Edn. UK: Pearson Education Ltd.

[60] Koen, P. A., Bertels, H. M. J., and Elsum, I. R. (2011). The three faces of business model innovation: challenges for established firms. Res. Technol. Manag. 54, 52-59.

[61] Tripsas, M., and Gavetti, G. (2000). Capabilities, cognition, and inertia: evidence from digital imaging. Strateg. Manag. J. 21, 1147-1161.

[62] Wirtz, B. W. (2011). Business Model Management - Design - Instruments - Success Factors. Wiesbaden: Gabler.

[63] Nørreklit, L. (2011). "Actors and reality: a conceptual framework for creative governance," in An Actor's Approach to Management. Conceptual Framework and Company Practices, eds M. Jakobsen, H. Nørreklit, and I.-L. Johansson, Copenhagen: DJØF Publishing, 7-37.

[64] Achtenhagen, L., Melin, L., and Naldi, L. (2013). Dynamics of business models - strategizing, critical capabilities and activities for sustained value creation. Long Range Plann. 46, 427-442.

[65] Ancona, D., Malone, T. W., Orlikowski, W. J., and Senge, P. M. (2007). In praise of the incomplete leader. Harv. Bus. Rev. 85, 92-100. 
[66] Teece, D. J. (2010). Business models, business strategy and innovation. Long Range Plann. 43, 172-194.

[67] Chaharbaghi, K., Fendt, C., and Willis, R. (2003). Meaning, legitimacy and impact of business models in fast-moving environments. Manag. Decis. 41, 372.

[68] Perkman and Spicer, What are business models?, in Research in the sociology of organizations, N. Phillips, G. Sewell, and D. Griffiths, Editors. 2010, Emerald Group Publishing Ltd: Bingley, United Kingdom. p. 265-276.

[69] Prahalad, C. K. and Bettis, R. A. (1986). The dominant logic: a new linkage between diversity and performance. Strateg. Manag. J. 7, 485-501.

[70] Bettis, R. A. and Prahalad, C. K. (1995). The dominant logic: retrospective and extension. Strateg. Manag. J. 16, 5-14.

[71] Tikkanen, H., Lamberg, J.-A., Parvinen, P., and Kallunki, J.-P. (2005). Managerial cognition, action and the business model of the firm. Manag. Decis. 43, 789-809.

[72] Aspara, J., Lamberg, J.-A., Laukia, A., and Tikkanen, H. (2013). Corporate business model transformation and inter-organizational cognition: the case of nokia. Long Range Plann. 46, 459-474.

[73] Linder, J. C., and Cantrell, S. (2000). Changing Business Models: Surveying the Landscape. Santa Cruz, CA: Institute for strategic change, Accenture.

[74] Cavalcante, S. A., Kesting, P., and Ulhøi, J. P. (2010). Business model dynamics: the central role of individual agency. Acad. Manag. Annu. Meeting Proc. 1-6.

[75] Sosna, M., Trevinyo-Rodríguez, R. N. and Velamuri, S. R. (2010). Business model innovation through trial-and-error learning: the naturhouse case. Long Range Plann. 43, 383-407.

[76] Markides, C. C. (2013). Business model innovation: what can the ambidexterity literature teach us? Acad. Manag. Perspect. 27, 313-323.

[77] Elfring, T., and Volberda, H. W. (2001). "Schools of thought in strategic management: fragmentation, integration or synthesis," in Rethinking Strategy, eds H. W. Volberda and T. Elfring, London: Sage Publications, Ltd, 1-26. 
34 A. B. Jensen

\section{Biography}

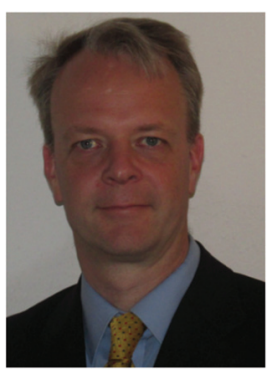

A. B. Jensen has a Ph.D. in business models and strategy from the Department of Leadership and Corporate Strategy at University of Southern Denmark and a M.Sc. in Business Administration from Copenhagen Business School. He has a professional background from the fast moving consumer goods, the venture industry, green energy industry and has a strong interest in the maritime sector. He has also been an entrepreneur and serves as a consultant and lecturer in strategy; marketing; organization; innovation and entrepreneurship, as well as turnaround management. 